Open Access

\title{
Characteristics and severity of asthma in children with and without atopic conditions: a cross-sectional study
}

\author{
Ali Arabkhazaeli ${ }^{1}$, Susanne J. H. Vijverberg ${ }^{1}$, Francine C. van Erp², Jan A. M. Raaijmakers' ${ }^{1}$ \\ Cornelis K. van der $\mathrm{Ent}^{2}$ and Anke H. Maitland van der Zee ${ }^{1^{*}}$
}

\begin{abstract}
Background: Childhood allergic diseases have a major impact on a child's quality of life, as well as that of their parents. We studied the coexistence of reported allergies in children who use asthma medication. Additionally, we tested the hypothesis that asthma severity is greater among children with certain combinations of co-morbid allergic conditions.

Methods: For this cross-sectional study, 703 children (ages 4 to 12 years) from the PACMAN cohort study were selected. All of the children were regular users of asthma medication. The study population was divided into nine subgroups according to parental-reported allergies of the child (hay fever, eczema, food allergy or combinations of these). In order to assess whether these subgroups differed clinically, the groups were compared for child characteristics (age, gender, family history of asthma), asthma exacerbations in the past year (oral corticosteroids (OCS) use; asthma-related emergency department (ED) visits), asthma control, fractional exhaled nitric oxide level (FeNO), and antihistaminic usage.

Results: In our study, $79.0 \%$ of the parents reported that their child suffered from at least one atopic condition (hay fever, food allergy and eczema), and one quarter of the parents (25.6\%) reported that their child suffered from all three atopic conditions. Having more than one atopic condition was associated with an increased risk of OCS use $(\mathrm{OR}=3.3,95 \% \mathrm{Cl}=1.6-6.6)$, $\mathrm{ED}$ visits $(\mathrm{OR}=2.3,95 \% \mathrm{Cl}=1.2-4.6)$ in the past year and inadequate short term asthma control $(\mathrm{OR}=1.9,95 \% \mathrm{Cl}=1.3-2.8)$.

Conclusions: Children who use asthma medication often also have other allergic conditions. Parental reported allergies were associated with a higher risk of more severe asthma (more asthma complaints and more asthma exacerbations).
\end{abstract}

Keywords: Allergy, Asthma, Atopic condition, Eczema, Exacerbation, FeNO, Food allergy, Hay fever

\section{Background}

Childhood allergic diseases have a major impact on a child's quality of life, as well as that of their parents [1]. Therefore, it is important to have a better understanding of the risk factors associated with the development of asthma in children, as well as the factors associated with more severe asthma. The term "allergy" refers to a

\footnotetext{
*Correspondence: a.h.maitland@uu.nl

'Division of Pharmacoepidemiology \& Clinical Pharmacology, Utrecht Institute for Pharmaceutical Sciences (UIPS), Faculty of Science, Utrecht University, P.O. Box 80082David de Wied Building, Universiteitsweg 99, Utrecht 3508 TB, The Netherlands

Full list of author information is available at the end of the article
}

hypersensitivity reaction initiated by immunologic mechanisms, and although all people are continuously exposed to different allergens, only a limited group of individuals experience adverse immunologic mechanisms [2]. Persistent asthma is often treated with inhaled corticosteroids (ICS) in combination with short acting beta agonists (SABA) as needed, or sometimes in more severe cases, long acting beta agonists and/or leukotriene antagonists [3]. When asthma is controlled, there should only be occasional recurrence of symptoms, and severe asthma exacerbations should be rare [4]. One of the risk factors for asthma severity that has been 
identified is atopy [5, 6]. Atopic individuals are prone to developing allergic symptoms. Asthma, food allergies, eczema, and hay fever are common childhood atopic conditions with an increasing prevalence in the western world [7].

In general, eczema peaks in the child's first years of life as an "entry point" for subsequent allergic disease, and consequently the prevalence of asthma and allergic rhinitis increases over time as sensitization develops [8].

Several studies have investigated the coexistence of food allergies and asthma, hay fever and asthma, or eczema and asthma [8-11]. However, most of these studies have only assessed the relationship between two conditions. They did not assess the effect of a combination of allergies, and they only focused on atopic patients. In this study, we examined the coexistence of allergies and the use of allergy related medication in a large cohort of children who use asthma medication and were recruited through community pharmacies. As a result of the inclusion of the participants from the community pharmacies, this cohort covered the whole spectrum of children with mild to severe asthma. Furthermore, we assessed the differences in the measurement of asthma severity among children with and without different allergies and combinations thereof.

\section{Methods}

\section{Study population}

At the time of this analysis, 744 children (ages 4 to 12 years) were included in the ongoing PACMAN (Pharmacogenetics of Asthma medication in Children: Medication with Anti-inflammatory effects) cohort study. Complete data on allergies was available for 703 children. The children were regular users ( $\geq 3$ prescriptions in the last two years and $\geq 1$ prescription in the last 6 months) of asthma medications (R03 on the ATC (Anatomical Therapeutic Chemical) coding system) and were recruited through community pharmacies in the Netherlands. The children and their parents were invited to their regular pharmacy for a study visit [12]. The design and rationale of the PACMAN study has been described elsewhere [12]. Data were collected with the help of pharmacists belonging to the Utrecht Pharmacy Practice Network for Education and Research (UPPER), and the work was conducted in compliance with the requirements of the UPPER institutional review board of the Department of Pharmacoepidemiology and Clinical Pharmacology, Utrecht University. The PACMAN study has been approved by the Medical Ethics Committee of the University Medical Centre Utrecht. Written, informed consent for all participants in the study was obtained from either the participants themselves, or, where participants were minors, a parent or guardian [12].

\section{Data collection}

The parents completed a questionnaire during the pharmacy visit. The questionnaire contained questions regarding general health, asthma and respiratory symptoms, allergy symptoms, medication use, adherence to medication (Medication Adherence Rating Scale (MARS) questionnaire [13]), socio-demographic factors, and asthma symptoms. In addition, the child's fractional exhaled nitric oxide level (FeNO) was measured with a handheld analyzer (Niox Mino, Aerocrine, Solna, Sweden).

To measure co-morbid atopic conditions, parents were asked: Has your child ever had a food allergy (FA) (itching, rash/hives, vomiting, diarrhea, runny nose, sneezing, stuffiness and cough)? Has your child ever had eczema? Has your child ever had hay fever (HF)?

The use of oral corticosteroids (OCS) and the amount of emergency department (ED) visits were used to measure asthma severity. Furthermore, the Dutch version of the 6-item Asthma Control Questionnaire (ACQ) was applied to assess current asthma control. ACQ $\geq 1.5$ was used as a cut-off value indicating poorly controlled asthma [14].

\section{Statistical analyses}

The study was a cross-sectional analysis in the baseline measurements of the PACMAN cohort study. The study population was stratified into nine subgroups according to the allergies that the parents had reported. The first three groups reported HF, FA, or eczema irrespective of whether or not they had also reported one or more of the other studied allergies. Then all possible combinations of

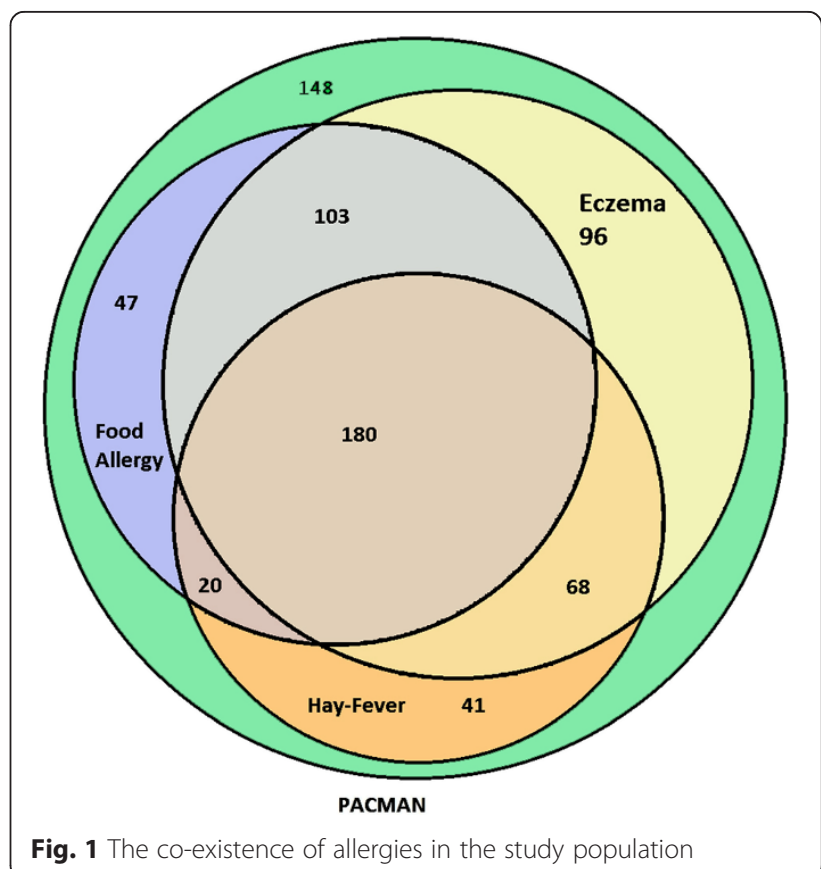


Table 1 Characteristics and antihistamines usage

The population

in the Venn diagram ${ }^{a}$
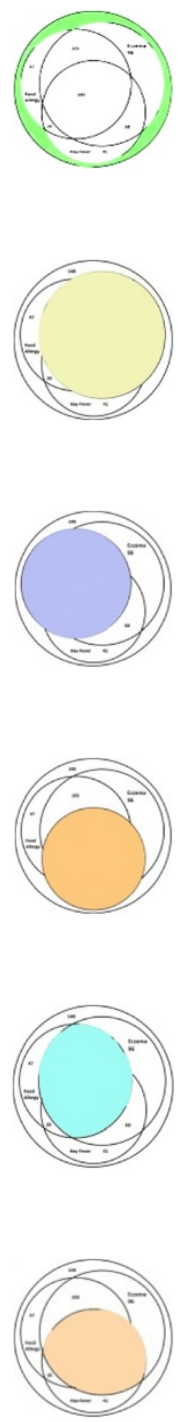

Eczema + Hay fever

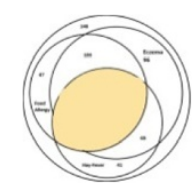

Study Population

Eczema

Food allergy

Hay fever
Number

(Percentage)

703

Without history of allergies

Food allergy + Eczema

Food allergy + Hay fever

$148(21.1 \%)$

447 (63.6 \%)

$350(49.8 \%)$

$309(44.0 \%)$

$283(40.3 \%)$

$248(35.3 \%)$

$200(28.5 \%)$
Mean Age \pm SD

$(P \text { Value })^{b}$

$8.4 \pm 2.4$

$8.1 \pm 2.4(.104)$

$11.0(.084)[6.0-27.0]$

$8.5 \pm 2.5(.485)$

$13.0(.222)[8.0-26.0]$

$8.4 \pm 2.5(.695)$

$13.0(.294)[8.0-27.0]$

$8.9^{d} \pm 2.3(.000)$

$15.0^{\mathrm{d}}(.005)[8.0-29.8]$

$8.5 \pm 2.5(.646)$

$14.0(.072)[8.3-27.8]$

$8.8^{d} \pm 2.4(.002)$

$15.0^{d}(.036)[8.5-27.5]$

$8.7^{\mathrm{d}} \pm 2.4(.035)$

15.0 (.153) [8.0 - 28.0] 
Table 1 Characteristics and antihistamines usage (Continued)

\begin{tabular}{|c|c|c|c|c|}
\hline & Food allergy + Eczema + Hay fever & $180(25.6 \%)$ & $8.8^{\mathrm{d}} \pm 2.4(.035)$ & $15.0(.099)[9.0-27.0]$ \\
\hline & At least two allergies & $371(52.8 \%)$ & $8.6 \pm 2.4(.109)$ & $14.0^{\mathrm{d}}(.029)[8.0-28.0]$ \\
\hline
\end{tabular}

${ }^{\mathrm{a}}$ For a larger diagram see Fig. 1

${ }^{\mathrm{b}}$ With independent samples T-test

'With Mann-Whitney test

${ }^{d} P$ Value $<0.05$

allergies were defined (FA + eczema, eczema + HF, FA + HF, FA + eczema + HF) (see Fig. 1 and Table 1).

The characteristics and asthma severity measures of these groups (age, gender, family history of asthma, breast feeding, FeNO, use of allergy medications, OSC usage, ED visits and ACQ) were compared between the groups of children with and without specific combination of atopic conditions (colored area in the first column of Table 1 and the rest of PACMAN population).

We used the independent samples T-test and the ChiSquare test where appropriate. As the distribution of FeNO was not normal, according to the KolomogorovSmirnov and the Shapiro-Wilk test, the Mann-Whitney test was used to compare median FeNO between different groups. Logistic regression was applied for multivariate analyses. Age, gender and use of antihistamines were considered potential confounding factors. The potential confounding factors were included in the multivariate model. The Odds Ratios (OR) for OCS use, ED visits and ACQ were adjusted for age and gender and reported with 95\% confidence intervals CI). Adjusting the OR for the use of antihistamines and adherence to therapy did not change the results (Table 4).

\section{Results}

\section{Co-existence of allergies}

In the study population, $79.0 \%(555 / 703)$ of the parents reported that their children had suffered from at least one of the assessed allergies. Eczema was the most common condition (63.6\%). Almost half of the study population reported a history of food allergy (49.8\%), and hay fever was reported by $44.0 \% 25.6 \%$ (180/703) of the participants reported symptoms of all three allergies (food allergy, eczema and hay fever), while $21.1 \%$ did not report any of these symptoms. (See Fig. 1 and Table 1).

\section{Baseline characteristics}

Characteristics of the study population are shown in Table 2.

The trends of the main allergic groups' age distributions are shown in Fig. 2. For hay fever an ascending trend is visible (Fig. 2). The mean age of the study population was 8.4 years. However, the mean age of the subgroup of children that reported having hay fever (irrespective of whether they had other allergies) was significantly higher $(8.9$ years, $p<0.001)$ (Table 1$)$. Also, the occurrence of hay fever increased from almost $20 \%$ in the 4-year-olds to more than $50 \%$ in the 12 -year-olds

Table 2 Characteristics of study population

\begin{tabular}{ll}
\hline Study population ( $n=703)$ & \\
\hline General characteristics & 62.0 \\
Male gender, \% & $8.4 \pm 2.5$ \\
Age, mean \pm SD & \\
Clinical characteristics & 63.6 \\
Parental-reported Eczema, \% & 49.8 \\
Parental-reported Food Allergy, \% & 44.0 \\
Parental-reported Hay fever, \% & 48.0 \\
Asthma family history ( One or more parents & \\
with history of asthma), \% & 30.6 \\
Antihistamine usage, \% & 87.8 \\
ICS usage, \% & 84.8 \\
SABA usage, \% & 23.5 \\
LABA usage, \% & 8.8 \\
LTRA usage, \% & 74.9 \\
Breast fed, \% & 13.0 (7.0 - 27.0) \\
Median FeNO (IQR) & 7.0 \\
OCS usage in the past year, \% & 6.3 \\
Asthma-related ED visit in the past year, \% & \\
\hline
\end{tabular}




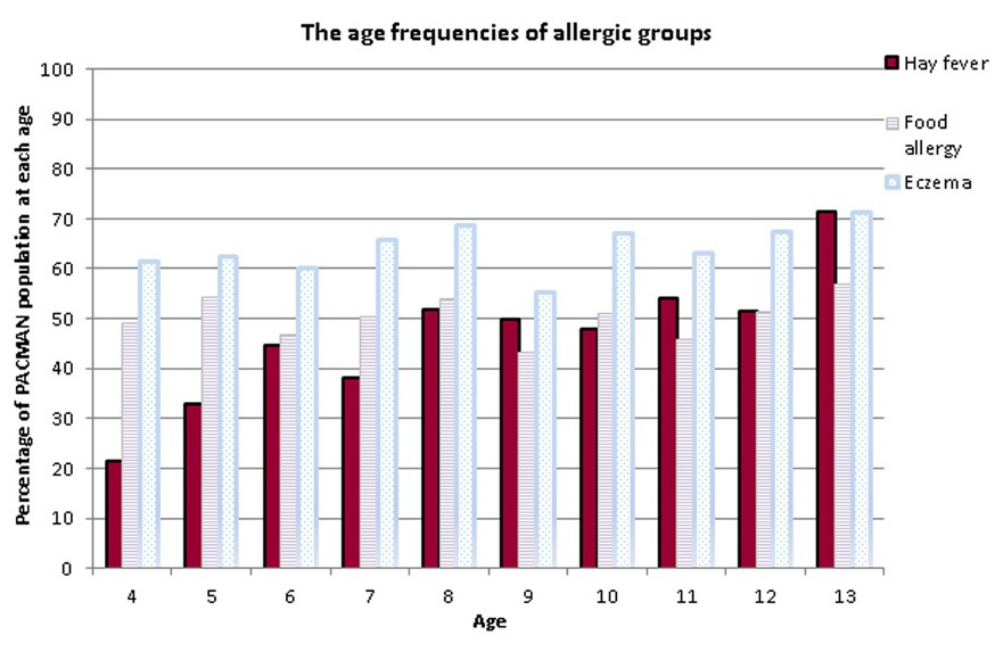

Fig. 2 The age frequencies of allergic groups in the study population

(Fig. 2). The frequency of children with a positive asthma family history (father or mother) in the total studied PACMAN population was $48.0 \%$. In the subgroup of children who reported having had hay fever, there was an even higher risk of a family history of asthma (55\%) compared to the children who did not report having had hay fever (45.0\%) (OR $=1.795 \%$ $\mathrm{CI}=1.2-2.3$ ). Furthermore, in the subgroup of children with a reported food allergy, there was a trend towards a higher risk of a family history of asthma $(51.2 \%$ to $48.8 \%$, OR $=1.395 \% \mathrm{CI}=1.0 \quad-1.8)$ (Table 3). The median of FeNO in the study population was 13.0 (Interquartile Range (IQR) $=7.0-27.0$ ). The children who reported having had hay fever had a significantly higher FeNO (median $=15.0, \mathrm{IQR}=8.0-$ 29.8, $p<0.01$ ) (Table 1). Gender or having been breastfed did not significantly differ between allergic subgroups.

\section{Oral antihistaminic drug usage}

Oral antihistaminic drugs were used by almost $30 \%$ of the study population. The top three oral antihistaminic drugs (Loratadine, Cetirizine and Fenistil) were equally distributed among all the allergy subgroups.

\section{Asthma outcomes}

Severity of asthma was assessed by OCS usage, ED visits and ACQ using both univariate and multivariate analyses. $9.1 \%$ of the children who reported eczema symptoms used OCS (Table 4). This was significantly higher when compared to the use of OCS in the non-eczema population (3.2\%) $(\mathrm{OR}=3.0,95 \% \mathrm{CI}=1.4-6.6)$. The use of OCS for the subgroup that had symptoms of food allergy was $9.6 \%$; this was also statistically significantly different compared to $4.3 \%$ of the non-food allergy population $(\mathrm{OR}=2.3,95 \% \mathrm{CI}=1.2-4.4)$. There was a

Table 3 Differences in asthma family history in the allergic subgroups

\begin{tabular}{|c|c|c|c|}
\hline \multirow[b]{2}{*}{ Group } & \multicolumn{2}{|c|}{ Asthma family history \% (P Value) } & \multirow{2}{*}{$\begin{array}{l}\text { Odds Ratio } \\
\text { (95\% Cl) }\end{array}$} \\
\hline & Present & Not present & \\
\hline Study population & 48.0 & & \\
\hline Without history of allergies & $44.0(.230)$ & 56.0 & $0.8(0.5-1.2)$ \\
\hline Eczema & $48.5(.741)$ & 51.5 & $1.1(0.8-1.4)$ \\
\hline Food allergy & $51.2(.096)$ & 48.8 & $1.3(1.0-1.8)$ \\
\hline Hay fever & $55.0^{\mathrm{a}}(.001)$ & 45.0 & $1.7^{\mathrm{a}}(1.2-2.3)$ \\
\hline Food allergy + Eczema & $51.5(.137)$ & 48.5 & $1.3(0.9-1.7)$ \\
\hline Eczema + Hay fever & $54.8^{\mathrm{a}}(.009)$ & 45.2 & $1.5^{\mathrm{a}}(1.1-2.1)$ \\
\hline Food allergy + Hay fever & $57.7^{\mathrm{a}}(.001)$ & 42.3 & $1.7^{\mathrm{a}}(1.2-2.4)$ \\
\hline Food allergy + Eczema + Hay fever & $57.5^{\mathrm{a}}(.004)$ & 42.5 & $1.7^{\mathrm{a}}(1.2-2.4)$ \\
\hline At least two allergies & $51.3(.070)$ & 48.7 & $1.3(1.0-1.8)$ \\
\hline
\end{tabular}

${ }^{a} \mathrm{P}$ Value $<0.05$ with chi-square test 
Table 4 Differences in outcomes of each subgroups in whole study population

\begin{tabular}{|c|c|c|c|c|c|c|c|c|c|}
\hline & \multirow[t]{3}{*}{$\begin{array}{l}\text { OCS usage \% } \\
\text { (P Value) }\end{array}$} & $\begin{array}{l}\text { Univariate } \\
\text { analysis }\end{array}$ & $\begin{array}{l}\text { Multivariate } \\
\text { analysis }^{\text {b }}\end{array}$ & \multirow{3}{*}{$\begin{array}{l}\text { E.D visit } \\
\text { in past year \% } \\
\text { ( } P \text { Value) }\end{array}$} & $\begin{array}{l}\text { Univariate } \\
\text { analysis }\end{array}$ & $\begin{array}{l}\text { Multivariate } \\
\text { analysis }^{b}\end{array}$ & \multirow{3}{*}{$\begin{array}{l}\text { Poorly } \\
\text { controlled } \\
\text { refer to ACQ-6 \% } \\
\text { (P Value) }\end{array}$} & \multirow{3}{*}{$\begin{array}{l}\text { Univariate } \\
\text { analysis } \\
\text { OR } \\
(95 \% \mathrm{Cl})\end{array}$} & \multirow{3}{*}{$\begin{array}{l}\text { Multivariate } \\
\text { analysis b } \\
\text { OR } \\
(95 \% \text { Cl) }\end{array}$} \\
\hline & & OR & OR & & OR & OR & & & \\
\hline & & $(95 \%$ Cl) & $(95 \% \mathrm{Cl})$ & & $(95 \% \mathrm{Cl})$ & $(95 \% \mathrm{Cl})$ & & & \\
\hline Study population & 7.0 & & & 6.3 & & & 18.2 & & \\
\hline Without history of allergies & $4.1(0.12)$ & $0.5(0.2-1.2)$ & $0.5(0.2-1.2)$ & $4.1(.215)$ & $0.6(0.2-1.4)$ & $0.5(0.2-1.3)$ & $14.3(.118)$ & $0.7(0.4-1.1)$ & $0.7(0.4-1.1)$ \\
\hline Eczema & $9.1^{\mathrm{a}}(.003)$ & $3.0^{a}(1.4-6.6)$ & $3.0^{\mathrm{a}}(1.4-6.6)$ & $8.1^{\mathrm{a}}(.010)$ & $2.7^{\mathrm{a}}(1.2-5.9)$ & $2.7^{\mathrm{a}}(1.2-6.0)$ & $20.4(.053)$ & $1.5(1.0-2.3)$ & $1.5^{\mathrm{a}}(1.0-2.4)$ \\
\hline Food allergy & $9.6^{\mathrm{a}}(.007)$ & $2.3^{\mathrm{a}}(1.2-4.4)$ & $2.3^{\mathrm{a}}(1.2-4.4)$ & $8.0(.068)$ & $1.8(1.0-3.4)$ & $1.8(0.9-3.4)$ & $21.3^{\mathrm{a}}(.039)$ & $1.5^{\mathrm{a}}(1.0-2.2)$ & $1.5^{\mathrm{a}}(1.0-2.2)$ \\
\hline Hay fever & $8.0(0.36)$ & $1.3(0.7-2.4)$ & $1.4(0.8-2.5)$ & $6.0(.765)$ & $0.9(0.5-1.7)$ & $1.1(0.6-2.1)$ & $22.7^{\mathrm{a}}(.007)$ & $1.7^{\mathrm{a}}(1.2-2.5)$ & $1.8^{\mathrm{a}}(1.2-2.7)$ \\
\hline Food allergy + Eczema & $11.6^{\mathrm{a}}(.000)$ & $3.2^{a}(1.7-6.0)$ & $3.3^{\mathrm{a}}(1.8-6.1)$ & $9.6^{\mathrm{a}}(.005)$ & $2.4^{\mathrm{a}}(1.3-4.6)$ & $2.5^{\mathrm{a}}(1.3-4.7)$ & $22.1^{\mathrm{a}}(.028)$ & $1.5^{\mathrm{a}}(1.0-2.3)$ & $1.6^{\mathrm{a}}(1.1-2.3)$ \\
\hline Eczema + Hay fever & $9.5(.056)$ & $1.8(1.0-3.2)$ & $1.8^{\mathrm{a}}(1.0-3.3)$ & $7.1(.557)$ & $1.2(0.6-2.3)$ & $1.4(0.7-2.7)$ & $24.5^{\mathrm{a}}(.002)$ & $1.9^{\mathrm{a}}(1.3-2.8)$ & $1.9^{\mathrm{a}}(1.3-2.9)$ \\
\hline Food allergy + Hay fever & $9.2(0.14)$ & $1.6(0.9-2.9)$ & $1.6(0.9-3.0)$ & $6.7(.776)$ & $1.1(0.6-2.2)$ & $1.2(0.6-2.5)$ & $25.4^{\mathrm{a}}(.002)$ & $1.9^{\mathrm{a}}(1.3-2.8)$ & $1.9^{\mathrm{a}}(1.3-2.9)$ \\
\hline $\begin{array}{l}\text { Food allergy + Eczema + } \\
\text { Hay fever }\end{array}$ & $10.3^{\mathrm{a}}(.045)$ & $1.9^{\mathrm{a}}(1.0-3.4)$ & $1.9(1.0-3.6)$ & $7.5(.467)$ & $1.3(0.7-2.5)$ & $1.5(0.7-2.9)$ & $25.3^{\mathrm{a}}(.005)$ & $1.8^{\mathrm{a}}(1.2-2.7)$ & $1.9^{\mathrm{a}}(1.2-2.8)$ \\
\hline At least two allergies & $10.1^{\mathrm{a}}(.001)$ & $3.2^{\mathrm{a}}(1.6-6.4)$ & $3.3^{\mathrm{a}}(1.6-6.6)$ & $8.4^{\mathrm{a}}(.020)$ & $2.2^{\mathrm{a}}(1.1-4.3)$ & $2.3^{\mathrm{a}}(1.2-4.6)$ & $22.4^{\mathrm{a}}(.003)$ & $1.9^{\mathrm{a}}(1.2-2.8)$ & $1.9^{\mathrm{a}}(1.3-2.8)$ \\
\hline
\end{tabular}

The referent group for all these odds ratios is the entire study population

ap Value $<0.05$ with logistic regression test

${ }^{\mathrm{b}}$ Adjusted for age and gender 
trend towards a higher risk for the use of OCS in all allergy subgroups. However, the group of children who did not report a history of allergic conditions did not have an increased risk for the use of OCS (Table 4).

Emergency department visits during the past year were significantly higher $(8.1 \%, \mathrm{OR}=2.7,95 \% \mathrm{CI}=1.2-6.0)$ in the population who had a history of eczema as compared to the rest of the population (3.2\%) (Table 4).

The Asthma Control Questionnaire (ACQ) was assessed in all the defined groups, and $18.2 \%$ of the total study population suffered from poorly controlled asthma. The frequencies of poorly controlled asthmatics in all allergic subgroups were significantly higher $(p<0.05)$ as compared to the non-allergic population. They were $21.3 \%, 20.4 \%$ and $22.1 \%$ in the populations with a history of eczema, food allergy or both, respectively. The frequencies of poorly controlled patients were even higher in all the subgroups that reported hay fever $(22.7 \%-25.4 \%)$ or more than one allergy $(22.4 \%)$ compared to the rest of study population (Table 4).

\section{Discussion}

In this large pharmacy-based study of children with a reported use of asthma medication, we found that the prevalence of children that reported symptoms of one or more allergy syndromes was high, and patients that reported more atopic conditions had a greater odds of more severe asthma.

In general, children with asthma and co-morbid allergic conditions were more often poorly controlled compared to their non-allergic peers. Furthermore, usage of OCS and asthma-related ED visits were more common in children who reported more than one atopic condition, which was approximately half of the study population. This indicates that the presence of a more complicated allergic phenotype significantly influences the severity of asthma [15].

To our knowledge, there is limited research that has studied the association of allergic comorbidities and asthma severity [16]. However several longitudinal studies have shown that approximately half of eczema patients will develop asthma, particularly patients with severe eczema [8]. A study by Roberts et al. showed that children with food allergies are around 6 times more likely to suffer from severe asthma later in life than children who did not have food allergies. Similarly, Priftis et al. showed that approximately $40 \%$ of children who were diagnosed with an egg and/or fish allergy in the first three years of their life reported current asthma symptoms at school age [17, 18]. Moreover, hay fever has been described as a major risk factor for asthma $[19,20]$. In the current study, eczema was the most frequently reported allergy among the three allergies (food allergy, eczema and hay fever), reported by $63 \%$ of the population (Table 2). A remarkably high percentage of the parents $(25.6 \%)$ reported that their children had experienced all three allergies (Fig. 1). The prevalence of food allergy in the current study was also very high (49.8\%). Earlier studies showed that the prevalence of food allergy varied between $3 \%$ and $35 \%$ [7]. Likewise a Dutch study reported a prevalence of (current) self-reported food allergy around $7.2 \%$ among school children in the Netherlands [21]. The high prevalence in our study may have been influenced by the fact that we asked whether the child had ever experienced symptoms. Some children might have only experienced symptoms in early childhood, and this may have caused a larger prevalence than the prevalence of current food allergy symptoms. Nevertheless, we do realize that self-reporting might lead to an overestimation. Unfortunately, data regarding provocation testing to confirm an actual diagnosis of food allergy were not available. However, it has been shown that results from screening questionnaires, comparable to the one we used in this study, were in concordance with results from specific IgE measurements and information obtained from patient records [22, 23].

When we assessed the effect of age on the development of allergic disease, we noticed that the occurrence of hay fever increased with age in our study population (Fig. 2). Moreover, the mean age of the hay fever group $(8.9 \pm 2.5)$ was significantly higher than the mean age in the overall study population (Table 2). The same trend was reported by Spergel et al. where the incidence of hay fever increased over time during childhood. This might be caused by sensitization developed through other allergic conditions [8]. Ghouri et al. showed an increase in the prevalence of hay fever during childhood in England as well [24]. On the other hand, age trends in the occurrence of the eczema were not observed. Spergel et al. reported age incidence of eczema peaks in the first years of life [8]. It might, therefore, be that our population was too old to observe this trend. The median FeNO level was significantly higher in the hay fever group. This is in alignment with other studies that confirm high FeNO levels in hay fever sufferers [25, 26].

Our study was limited by the lack of physicians' diagnoses on allergic diseases or objective immunological test results. We used a questionnaire to obtain information about the history of allergic conditions. Other studies (such as ISAAC [27]) have also used questionnaire data. We realize, however, that this questionnaire data might differ from objective tests, and the occurrence of allergic diseases might therefore have been overestimated due to the use of parental-reported data. However, the strength of our study is in the selection of a large set of asthmatic children through community pharmacies. Our population represents a cross-section of the everyday pediatric asthma population that 
varies in the severity of the disease, health care utilization and asthma control.

\section{Conclusions}

In conclusion, our study suggests that children with asthma and co-morbid atopic conditions are at risk for more exacerbations and less well-controlled asthma in comparison to children who did not report allergies. The children who were reported to have had more than one allergic co-morbidity were especially at risk of having less well controlled asthma and more severe exacerbations. This may have clinical implications, such as more unscheduled health care visits and hospitalizations, as these patients may experience more severe asthma. These children should be carefully monitored and might benefit from asthma/allergy specialist care at an earlier stage.

\section{Abbreviations}

ACQ: Asthma Control Questionnaire; ATC: Anatomical Therapeutic Chemical; $\mathrm{Cl}$ : confidence interval; ED: emergency department; FA: food allergy; FeNO: fractional exhaled nitric oxide level; HF: hay fever; ICS: Inhaled Corticosteroids; IQR: Interquartile Range; MARS: Medication Adherence Rating Scale; OCS: oral corticosteroids; OR: Odds Ratios; PACMAN: Pharmacogenetics of Asthma medication in Children: Medication with Anti-inflammatory effects; SABA: short acting beta agonists; UPPER: Utrecht Pharmacy Practice Network for Education and Research.

\section{Competing interests}

Francine C. van Erp declares that she has no competing interests. Susanne J.H. Vijverberg had been paid by an unrestricted grant from GlaxoSmithKline (GSK). Jan A. M. Raaijmakers is a part-time professor at the Utrecht University and he was Vice-president External Scientific Collaborations for GSK in Europe, and holds stock in GSK. Anke-Hilse Maitland-van der Zee received an unrestricted grant from GSK. Cornelis K. van der Ent received unrestricted grants from GSK and Grunenthal. Furthermore, the Department of Pharmacoepidemiology and Clinical Pharmacology, Utrecht Institute for Pharmaceutical Sciences, employing authors Ali Arabkhazaeli, Susanne J.H. Vijverberg, Jan A.M. Raaijmakers, and Anke-Hilse Maitland-van der Zee, has received unrestricted research funding from the Netherlands Organisation for Health Research and Development (ZonMW), the Dutch Health Care Insurance Board (CVZ), the Royal Dutch Pharmacists Association (KNMP), the private-public funded Top Institute Pharma (http://www.tipharma.nl website, includes co-funding from universities, government, and industry), the EU Innovative Medicines Initiative (IMI), EU 7th Framework Program (FP7), the Dutch Medicines Evaluation Board, the Dutch Ministry of Health and industry (including GSK, Pfizer, and others).

\section{Authors' contributions}

AA carried out the study design, analysis and interpretation of data, and drafted the manuscript. SV carried out the acquisition of data, participated in interpretation and helped to draft the manuscript. FE participated in interpretation. JR participated in study design and interpretation. CKE participated in study design and interpretation. AM contributed to conception and design of the study, and participated in its design and coordination and helped to draft the manuscript. All authors read and approved the final manuscript.

\section{Acknowledgements}

The authors wish to thank the children and the parents of the PACMAN cohort study, as well as UPPER and the participating pharmacies for their cooperation. Furthermore, we acknowledge the field workers for their valuable efforts. Susanne J.H. Vijverberg had been paid by an unrestricted grant from GlaxoSmithKline (GSK). Jan A. M. Raaijmakers is a part-time professor at the Utrecht University and he was Vice-president External Scientific Collaborations for GSK in Europe, and holds stock in GSK. Anke-Hilse
Maitland-van der Zee received an unrestricted grant from GSK. Cornelis K. van der Ent received unrestricted grants from GSK and Grunenthal. Furthermore, the Department of Pharmacoepidemiology and Clinical Pharmacology, Utrecht Institute for Pharmaceutical Sciences, employing authors Ali Arabkhazaeli, Susanne J.H. Vijverberg, Jan A.M. Raaijmakers, and Anke-Hilse Maitland-van der Zee, has received unrestricted research funding from the Netherlands Organisation for Health Research and Development (ZonMW), the Dutch Health Care Insurance Board (CVZ), the Royal Dutch Pharmacists Association (KNMP), the private-public funded Top Institute Pharma (http://www.tipharma.nl website, includes co-funding from universities, government, and industry), the EU Innovative Medicines Initiative (IMI), EU 7th Framework Program (FP7), the Dutch Medicines Evaluation Board, the Dutch Ministry of Health and industry (including GSK, Pfizer, and others).

\section{Author details}

1Division of Pharmacoepidemiology \& Clinical Pharmacology, Utrecht Institute for Pharmaceutical Sciences (UIPS), Faculty of Science, Utrecht University, P.O. Box 80082David de Wied Building, Universiteitsweg 99, Utrecht 3508 TB, The Netherlands. ${ }^{2}$ Department of Pediatric Respiratory Medicine, Wilhelmina Children's Hospital, University Medical Centre Utrecht, Lundlaan 6, Utrecht 3584 EA, The Netherlands.

Received: 1 September 2014 Accepted: 8 October 2015

Published online: 06 November 2015

\section{References}

1. Covaciu C, Bergstrom A, Lind T, Svartengren M, Kull I. Childhood allergies affect health-related quality of life. J Asthma. 2013;50(5):522-8.

2. Nauta AJ, Engels F, Knippels LM, Garssen J, Nijkamp FP, Redegeld FA. Mechanisms of allergy and asthma. Eur J Pharmacol. 2008;585(2-3):354-60.

3. Barnes J. Chapter 254. Asthma. In: Longo D, Fauci A, Kasper D, Hauser S, Jameson J, Loscalzo J, editors. Harrison's Principles of Internal Medicine. 18th ed. New York: McGraw-Hill; 2012.

4. Bateman ED, Hurd SS, Barnes PJ, Bousquet J, Drazen JM, FitzGerald M, et al Global strategy for asthma management and prevention: GINA executive summary. Eur Respir J. 2008;31(1):143-78.

5. Hon KL, Wang SS, Leung TF. The atopic march: from skin to the airways. Iran J Allergy Asthma Immunol. 2012;11(1):73-7.

6. Schwindt CD, Bacchus H, Leu SY, Tjoa T, Klebanova Y, Delfino RJ. Characterization of the asthmatic population of St. Vincent and the Grenadines: asthma severity levels and atopic sensitization. J Asthma. 2010;47(8):871-7.

7. Kewalramani A, Bollinger ME. The impact of food allergy on asthma. J Asthma Allergy. 2010;3:65-74.

8. Spergel JM, Paller AS. Atopic dermatitis and the atopic march. J Allergy Clin Immunol. 2003;112(6 Suppl):S118-27.

9. Branum AM, Lukacs SL. Food allergy among children in the United States. Pediatrics. 2009;124(6):1549-55.

10. Eichenfield LF, Hanifin JM, Beck LA, Lemanske Jr RF, Sampson HA, Weiss ST, et al. Atopic dermatitis and asthma: parallels in the evolution of treatment. Pediatrics. 2003;111(3):608-16.

11. Morgan WJ, Crain EF, Gruchalla RS, O'Connor GT, Kattan M, Evans III R, et al. Results of a home-based environmental intervention among urban children with asthma. N Engl J Med. 2004;351(11):1068-80.

12. Koster ES, Raaijmakers JA, Koppelman GH, Postma DS, van der Ent CK, Koenderman $\mathrm{L}$, et al. Pharmacogenetics of anti-inflammatory treatment in children with asthma: rationale and design of the PACMAN cohort. Pharmacogenomics. 2009;10(8):1351-61.

13. Menckeberg T, Bouvy M, Bracke M. Adherence to inhaled corticosteroids and patient perception: towards a better understanding and individualised care. Utrecht: Utrecht University; 2008.

14. Juniper EF, Bousquet J, Abetz L, Bateman ED, GOAL Committee. Identifying 'well-controlled' and 'not well-controlled' asthma using the Asthma Contro Questionnaire. Respir Med. 2006;100(4):616-21.

15. Schwindt CD, Tjoa T, Floro JN, McLaren C, Delfino RJ. Association of atopy to asthma severity and medication use in children. J Asthma. 2006:43(6):439-46.

16. Just J, Gouvis-Echraghi R, Rouve S, Wanin S, Moreau D, Annesi-Maesano I. Two novel, severe asthma phenotypes identified during childhood using a clustering approach. Eur Respir J. 2012;40(1):55-60. 
17. Roberts G, Patel N, Levi-Schaffer F, Habibi P, Lack G. Food allergy as a risk factor for life-threatening asthma in childhood: a case-controlled study. J Allergy Clin Immunol. 2003;112(1):168-74.

18. Priftis KN, Mermiri D, Papadopoulou A, Papadopoulos M, Fretzayas A Lagona E. Asthma symptoms and bronchial reactivity in school children sensitized to food allergens in infancy. J Asthma. 2008:45(7):590-5.

19. Pawankar R, Bunnag C, Chen Y, Fukuda T, Kim YY, Le LT, et al. Allergic rhinitis and its impact on asthma update (ARIA 2008)-western and AsianPacific perspective. Asian Pac J Allergy Immunol. 2009;27(4):237-43.

20. Lin J, Su N, Liu G, Yin K, Zhou X, Shen H, et al. The impact of concomitant allergic rhinitis on asthma control: a cross-sectional nationwide survey in China. J Asthma. 2014;51(1):34-43.

21. Brugman E, Meulmeester JF, Spee-van der Wekke A, Beuker RJ, Radder JJ, Verloove-Vanhorick SP, et al. Prevalence of self-reported food hypersensitivity among school children in The Netherlands. Eur J Clin Nutr. 1998;52(8):577-81.

22. Lakwijk N, Van Strien RT, Doekes G, Brunekreef B, Gerritsen J. Validation of a screening questionnaire for atopy with serum IgE tests in a population of pregnant Dutch women. Clin Exp Allergy. 1998;28(4):454-8

23. Tuokkola J, Kaila M, Pietinen P, Simell O, Knip M, Virtanen SM. Agreement between parental reports and patient records in food allergies among infants and young children in Finland. J Eval Clin Pract. 2008;14(6):984-9.

24. Ghouri N, Hippisley-Cox J, Newton J, Sheikh A. Trends in the epidemiology and prescribing of medication for allergic rhinitis in England. J R Soc Med. 2008;101(9):466-72.

25. Gratziou C, Lignos M, Dassiou M, Roussos C. Influence of atopy on exhaled nitric oxide in patients with stable asthma and rhinitis. Eur Respir J. 1999;14(4):897-901.

26. Buchvald F, Baraldi E, Carraro S, Gaston B, De Jongste J, Pijnenburg MW, et al. Measurements of exhaled nitric oxide in healthy subjects age 4 to 17 years. J Allergy Clin Immunol. 2005;115(6):1130-6.

27. ISAAC Methodology. [http://isaac.auckland.ac.nz/story/methods/ methods.php]

\section{Submit your next manuscript to BioMed Central and take full advantage of:}

- Convenient online submission

- Thorough peer review

- No space constraints or color figure charges

- Immediate publication on acceptance

- Inclusion in PubMed, CAS, Scopus and Google Scholar

- Research which is freely available for redistribution 